\title{
Passive Range of Motion
}

National Cancer Institute

\section{Source}

National Cancer Institute. Passive Range of Motion. NCI Thesaurus. Code C63512.

A measure of how far a joint can move when it is being manipulated by someone other than the patient. 